\title{
Performance of the Biocompatible Surfactant Tween 80, for the Formation of Microemulsions Suitable for New Pharmaceutical Processing
}

\author{
Cristina Prieto and Lourdes Calvo \\ Departamento de Ingeniería Química, Facultad de Ciencias Químicas, Universidad Complutense de Madrid, \\ Avenue Complutense s/ $n$, 28040 Madrid, Spain
}

Correspondence should be addressed to Lourdes Calvo; lcalvo@quim.ucm.es

Received 30 April 2013; Accepted 24 June 2013

Academic Editor: Rassoul Dinarvand

Copyright (C) 2013 C. Prieto and L. Calvo. This is an open access article distributed under the Creative Commons Attribution License, which permits unrestricted use, distribution, and reproduction in any medium, provided the original work is properly cited.

\begin{abstract}
The aim of this work was to investigate the phase behaviour and the structure of the $\mathrm{n}$-hexane/water emulsions based on a nonionic, nontoxic and biocompatible surfactant, Tween 80. This system is of interest for new pharmaceutical techniques based on supercritical fluids to form nano- and encapsulated particles. However, it showed a lack of stability denoted by large areas of macroemulsion. For this reason, the effect of additives (alcohols and brine) and external variables (temperature) were explored. The replacement of water by brine caused negligible impact due to the nonionic character of Tween 80 . On the contrary, the presence of an alcohol (ethanol or 1-butanol) enhanced the solubility of the surfactant in the oil phase and decreased the mixture viscosity, resulting in improved surface activity. Similar results were obtained by raising the temperature until the cloud point was reached $\left(60^{\circ} \mathrm{C}\right)$. With these modifications, microemulsions at relatively low concentrations of surfactant (around $\left.30 \%\right)$ and within a broad interval of compositions could be obtained, widening their possible use in pharmaceuticals manufacturing (such as controlled drug delivery, enzymatic reactions, or excipient processing). The understanding of the surfactant performance could be further used to substitute the n-hexane by a greener solvent, such as supercritical $\mathrm{CO}_{2}$.
\end{abstract}

\section{Introduction}

Under the principles of sustainable development and being environmentally friendly, a new field, called green chemistry, has been developed based on waste minimisation, energy efficiency, nonhazardous raw materials, solvents or products, inherently safe chemicals processes, and on renewable feedstocks [1]. In this sense, the global pharmaceutical corporations have encouraged the integration of green chemistry and green engineering into the pharmaceutical industry [2]. Between the key research areas for sustainable manufacturing, emulsions have generated a lot of interest, due to the fact that many pharmaceutical processes include direct or indirect contact with some kinds of emulsions in some of their innumerable applications.

The term emulsion designates a system composed of two immiscible liquids, one dispersed in the other, in a more or less stable way [3]. It is possible to make these two liquids compatible so that the mixture could be manipulated, administered, and used without breaking.

The general structure of emulsions comprises one phase formed by water or a water solution and another phase formed by an organic solvent insoluble in water, which is known as oil. Such emulsions are usually of two classes: oil in water $(\mathrm{O} / \mathrm{W})$ or water in oil $(\mathrm{W} / \mathrm{O})$, where the first liquid comprises the dispersed phase and the second one the continuous phase.

They can be classified into macroemulsions (which generally are called emulsions) and microemulsions. Although terminology suggests that colloid size is the determining factor, there are important differences in properties, which make their separate study interesting.

Microemulsions are optically transparent, thermodynamically stable, isotropic mixtures of water, organic solvent, and surfactant [4] and typically consist of disperse phase droplets from 2 to $50 \mathrm{~nm}$ in diameter. In contrast 
to microemulsions, macroemulsions contain relatively large droplets $(>0.1 \mu \mathrm{m})$ that are opaque and, although no longer thermodynamically stable, may be kinetically stable for long periods. Furthermore, macroemulsions may be formed with higher interfacial tensions between water and oil than in the case of microemulsions and, thus, with lower values of surfactant adsorption at the interface. Therefore, macroemulsions may be formed for a wider variety of surfactants than microemulsions, and with lower surfactant concentrations. This becomes especially important when dealing with expensive surfactants.

An influential factor on emulsion formation and stability is the surfactant, and its action depends on its structure and nature of the two phases. These agents could be classified according to the chemical group of the hydrophilic head into ionic, which could be further divided into anionic and cationic, nonionic, and zwitterionic.

The design of new functional surfactants exhibiting additional chemical and biological functionalities attracts a large interest nowadays, due to new potential applications [5]. The selected agent to carry out this study was Tween 80 , an especially attractive nonionic surfactant, non-toxic, environmental friendly, biocompatible, and commercially inexpensive [6].

In recent years, a great amount of theoretical and experimental work has been developed devoted to different kinds of emulsions to try to expand the knowledge of these systems with regard to their molecular structure and formation process [7]. Since technical applications of these systems in pharmacy, cosmetics, and nutraceutics among others increasingly require more systematic optimisation of system properties, a complete revolution in the conception, design, production, and characterization of the emulsions in a variety of chemical and industrial processes has been made $[8,9]$. However, very little work has focused on researching the formation, phase behaviour, and structure of both emulsions and microemulsions from completely non-toxic and safe materials, and consequently the widespread pharmaceutical use of microemulsions has been limited, by the requirement for pharmaceutically acceptable ingredients.

We have selected $n$-hexane, thinking of the multiple possibilities of the system. First, this system is very useful for nanoparticles formation, either by conventional techniques, such as solvent evaporation or spray drying, or by new techniques using supercritical fluids, such as (supercritical fluid extraction of emulsions) SFEE and (concentrated powder form) technology CPF. These techniques are based on the extraction of the organic solvent, leading to the formation of the nanoparticles, which can be even encapsulated during the same process. The use of a microemulsion supposes a better control of nanoparticle size and morphology, because it acts as a template. Despite being an organic solvent, the use of $n$-hexane is permitted in this kind of extractions, even in the food industry. Second, the study of this system provides us with the needed knowledge to substitute the organic solvent by a supercritical fluid, since at supercritical conditions, the $\mathrm{CO}_{2}$ has a very similar density to the $\mathrm{n}$-hexane. Microemulsions with supercritical fluids were formed by fluorinated surfactants up to now [10]. Nonetheless, their use in pharmaceutical industry requires biocompatible systems, which could be used to synthesize nanoparticles, as well as for biotechnological reactions [11].

The aim of this paper was to study comprehensively the n-hexane/water emulsions, using Tween 80 , a non-toxic and biocompatible surfactant. The use of additives (alcohols and brine) and the variation of external variables (temperature) were investigated to modify the stability. This type of in-depth analysis with a biocompatible surfactant was not made up to our knowledge; nevertheless, it is of fundamental importance for the selection of operational conditions for further research as well as the development of new applications.

\section{Experimental Section}

2.1. Materials. Tween 80 (polyoxyethylene (20) sorbitan monooleate $\left[\mathrm{C}_{24} \mathrm{H}_{46} \mathrm{O}_{6} \cdot\left[\mathrm{C}_{2} \mathrm{H}_{4} \mathrm{O}\right]_{w+x+y+z}\right.$ for $w+x+y+$ $z=20]$ ), n-hexane ( $\geq 99 \%(\mathrm{GC})$ ), 1-butanol (99.9\%), ethanol (99.5\%), and sodium chloride were all from Sigma Aldrich and used as received. Millipore water was used throughout the study.

2.2. Sample Preparation. The Tween $80 /$ water/n-hexane mixtures were prepared using screw-cap tubes. Nineteen compositions in mass were chosen to cover the whole ternary phase map, with a final sample mass of $5 \mathrm{~g}$. For each of the experiments, a table of experiments was built similarly to Table 1.

Two types of additives were used: alcohols (1-butanol and ethanol) and brine. In order to study the influence of alcohols, a mixture of alcohol and surfactant was made in proportion 1:1 in volume; for example, in sample 1, the $80 \%$ of surfactant in this case represents $80 \%$ of mixture surfactant + cosurfactant. In the case of brine, instead of using Millipore water, $2 \% \mathrm{NaCl}$ brine was used.

To prepare the emulsions, the following steps were carried out.

(1) Addition of the adequate quantity of oil.

(2) Addition of the adequate quantity of surfactant and cosurfactant (if it was necessary).

(3) Mechanical shaking for $1 \mathrm{~min}$ on the vortex.

(4) Addition of the adequate quantity of water.

(5) Vigorous mechanical shaking for $5 \mathrm{~min}$ on the vortex, due to the high viscosity of the surfactant in order to guarantee a homogeneous dispersion.

(6) Control of temperature by placing the tube within a thermostatic water bath.

(7) Left at rest during $24 \mathrm{~h}$ before analysis.

Experiments were developed between room temperature and boiling point of $n$-hexane, concretely at $25,30,40,50$, and $60^{\circ} \mathrm{C}$.

2.3. Determination of Phase Behaviour. In order to study the behaviour of Tween $80 /$ water/n-hexane emulsions, visual observation and UV-Vis spectroscopy tests were carried out. 
TABLE 1: Table of experiments built for each system.

\begin{tabular}{lccc}
\hline \multirow{2}{*}{ Number of the sample } & \multicolumn{3}{c}{ Composition (mass \%) } \\
& Water & n-hexane & Surfactant \\
\hline 1 & 10 & 10 & 80 \\
2 & 10 & 20 & 70 \\
3 & 10 & 40 & 50 \\
4 & 10 & 60 & 30 \\
5 & 10 & 80 & 10 \\
6 & 20 & 10 & 70 \\
7 & 20 & 20 & 60 \\
8 & 20 & 40 & 40 \\
9 & 20 & 60 & 20 \\
10 & 20 & 70 & 10 \\
11 & 40 & 10 & 50 \\
12 & 40 & 20 & 40 \\
13 & 40 & 40 & 20 \\
14 & 40 & 50 & 10 \\
15 & 60 & 10 & 30 \\
16 & 60 & 20 & 20 \\
17 & 60 & 30 & 10 \\
18 & 80 & 10 & 10 \\
19 & 35 & 35 & 30 \\
\hline
\end{tabular}

All samples were measured in triplicate, and therefore the result shown is a mean value. With all this information, phase maps were constructed for all samples and in all operational conditions studied.

2.3.1. Visual Observations. The first step for determining the phase behaviour, once the emulsion was created, was to make a visual inspection. Different results were obtained in colour and in texture as well as in transparency. Microemulsions were identified as transparent samples, whilst showing phase separation (Winsor I, II, or III); in the same way, samples with at least one turbid phase were considered macroemulsions, and they were stable over several days. In both, macroemulsion and microemulsions, there were cases of phase separation of the component in excess. Highly viscous samples were also observed and classified as gel-like.

2.3.2. UV-Vis Spectroscopy. Observations made by naked eye were corroborated by absorbance measurements. Absorbance of each sample was measured in an MRC UV 1800 spectrophotometer at $340 \mathrm{~nm}$ [12], taking the n-hexane as the (white) reference solution.

A calibration curve of surfactant water was created to establish a correlation between absorbance and concentration of surfactant. So when absorbance of the sample coincided with the calibration curve, this indicated that it was a transparent microemulsion. On the contrary, macroemulsions were obtained with a high absorbance value. For each one of the systems and each temperature, a graphic similar to Figure 1 was created. Represented data were the average of three measurements. The standard deviation, analysed over a sample measured six times, was \pm 0.030 .

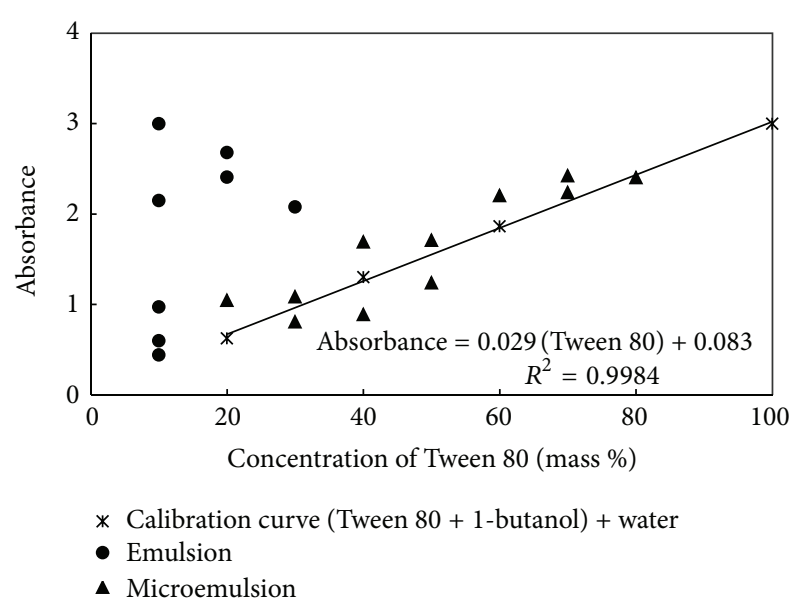

FIGURE 1: Absorbance measurements for the system: Tween $80+$ 1-butanol/water $/ \mathrm{n}$-hexane at $30^{\circ} \mathrm{C}$.

2.3.3. Construction of Phase Maps. Ternary mixtures were represented on the triangular phase map in terms of mass percentages of the components, where the apex designates $100 \%$ of each component, sides represent binary mixtures, and points inside the triangle represent ternary mixtures.

If the system had four components with related concentrations, a quaternary representation was needed [13], but it was simplified by taking the constant ratio between two components, generating a pseudoternary map. Therefore masspseudoternary phase maps were used when a cosurfactant, 1-butanol or ethanol, was added, in both cases in a proportion of $1: 1$ in volume to Tween 80 .

To show the evolution of the map as a function of the temperature, a prism of phases was constructed by the superposition of the ternary phase maps at each one of the temperatures studied. All the presented observations were confirmed by at least three samples.

2.4. Determination of the Emulsions Structure by Conductimetry. The structure and composition of one emulsion are highly related; however, the excess of the solvents is indicative but not determinative of the emulsion structure. Conductimetry measurements were then performed to conclude the structure of the emulsion. This simple technique allows classification of the emulsion structure into $\mathrm{O} / \mathrm{W}$, bicontinuous, or $\mathrm{W} / \mathrm{O}$.

A Eutech Instruments CON510 conductivity was used to measure the conductance, which is defined as the ability to conduct electrical current between two points. In this case, it measured the conductance of a solution enclosed in a cube of $1 \mathrm{~cm}^{3}$. Electrical conductance measurements in emulsions with nonionic surfactants had to be done in the presence of a solved electrolyte, which gives the electric charge needed for transport. Due to Tween 80 not being conductive, $2 \%$ brine was used instead of the aqueous phase.

The conductivity of $\mathrm{O} / \mathrm{W}$ emulsions had the same order of magnitude as the aqueous phase conductivity, around several $\mathrm{mS} / \mathrm{cm}$, due to sodium and chloride ions moving along the water channel, showing the conducting nature of 
the emulsion, whilst W/O emulsion conductivity was usually around 100 or 1000 times smaller, since the mobility of ions was restricted due to surrounding strong insulating oil which disconnects the water network. Bicontinuous phase displayed high or low conductivity depending on what the external phase was, water or oil.

\section{Results and Discussion}

This research focused on the formation and stability of Tween 80/water/n-hexane emulsions; therefore, the first step was the determination of the phase behaviour through techniques such as visual observation and UV-Vis spectroscopy, which allowed classification of the systems into macro- and microemulsions. All the information was gathered and represented in phase maps, at all studied conditions. Additives (alcohols and brine) and external variables (temperature) were used in order to modify the original phase map according to the potential requirements of the different applications. The final step was the determination of the emulsion structure, using conductimetry measurements.

3.1. Determination of Phase Behaviour. The phase behaviour of the Tween $80 /$ water/n-hexane system was obtained by visual observation and absorbance measurements of each sample. With all this information, a ternary phase map was constructed. An example at $25^{\circ} \mathrm{C}$ is shown in Figure 2.

The system shows three regions represented with different shadings: area without shading or microemulsion, corresponding with sample 1; area with a light grey shading or macroemulsion; a third area with dark grey shading or gellike area, corresponding to samples 3, 4, 5, 9, and 19. The latter area was mainly provoked by the high viscosity of Tween 80 at room temperature. Additives and temperature differences were used to correct this negative effect.

3.1.1. Effect of Additives. Temperature, salinity, and type of alcohol are the common variables used to manipulate phase behaviour and emulsion structure, because these parameters modify the interactions between components with the polar head of the surfactant [14]. Pressure provides a completely different mechanism of control of the emulsion, due to the main effect being created on the hydrophobic tail [15]; however, the effect of pressure is weak compared with that of temperature, so it is usually kept constant [16].

Effect of an Added Alcohol. Some surfactants need the presence of other active surface agents, which are called cosurfactants, to generate microemulsions [2, 17]. These compounds often belong to the group of components able to form hydrogen bonds and/or which have a strong attraction to the surfactant. Such additives can be long chain amines, amides, fatty acids, ethoxylates, chloroform, and so forth, but frequently oil or water-soluble alcohols are used.

For the system Tween 80/water/n-hexane, two alcohols were selected: 1-Butanol and ethanol. 1-butanol is frequently used as an additive and ethanol was tested because it is less toxic for pharmaceutical and food applications. First of all, the power of both alcohols as emulsifying agents by

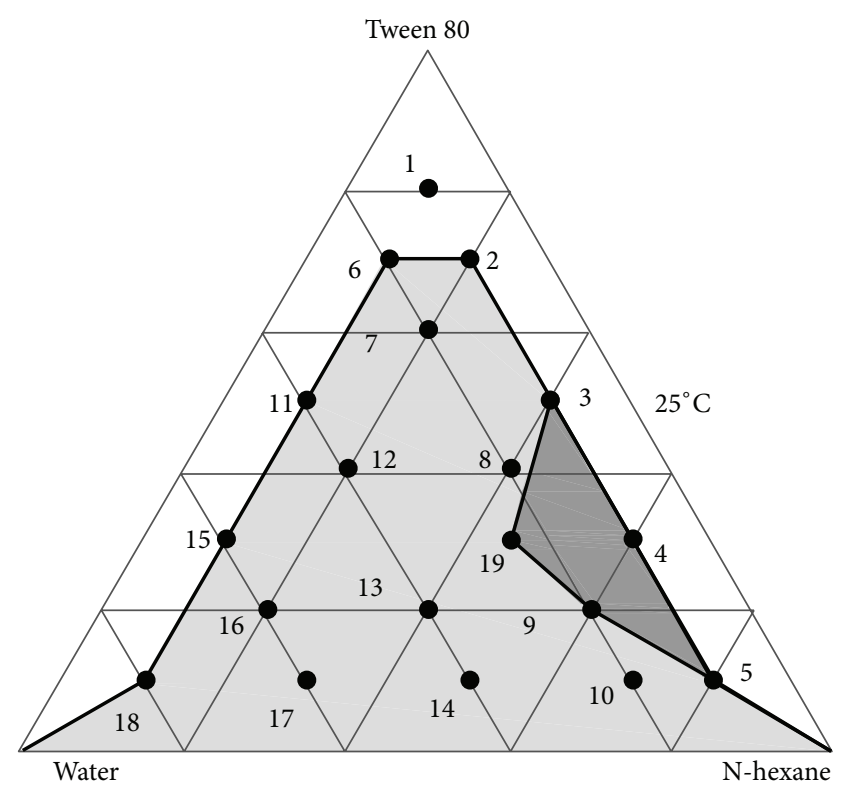

Figure 2: Ternary phase map of the system: Tween 80/water/nhexane at $25^{\circ} \mathrm{C}$.

themselves was investigated, resulting in the finding that they were not capable of stabilising the water/n-hexane system, so the emulsion broke down when the shaking was stopped. However, when used as cosurfactants of Tween 80 in the ratio of $1: 1 \mathrm{v} / \mathrm{v}$, a better solubilisation between phases and a decrease of the mixture viscosity were reached, achieving a higher stabilisation of the system. Indeed, the emulsion region diminished, increasing the microemulsion one, and the gel-like region disappeared, as the base of the phase prisms in Figures 4 and 5 showd. When comparing both cosurfactants, 1-butanol proved to be more efficient at room temperature.

It is believed that the alcohol joins the interface of the micelle, placing itself among surfactant heads, creating an increase of the dielectric constant and the ionisation degree [18]. The penetration of the alcohol into the interfacial film reduces the repulsion of the long hydrophobic tails of the surfactant at the interface, favouring its dissolution in the oil phase. Consequently, an increase in the length of the cosurfactant hydrocarbon chain increases the superficial activity (Traube's rule) [18] so that the micelle reaches a greater degree of stabilisation. At the molecular level, this effect could be explained as follows: the chain length of the surfactant must be equal to the sum of the cosurfactant chain length and the oil chain length in order to minimise disruption in the interfacial region. When chain lengths are not the same, the resulting monolayer film is disrupted easily. Consequently, microemulsion stability should be higher for 1-butanol than for ethanol, as indeed observed.

The presence of the alcohol also affects the physical properties of the water. The alcohol disrupts the water structure, creating an increase in the lipophilic character of the Tween 80 [19]. Furthermore, the alcohol provokes a decrease in the mixture viscosity [20]; therefore, the big 
molecules such as Tween 80 can reach the interface faster. However, the presence of the alcohol in the mixture also promotes a decrease in the cloud point of the surfactant (see temperature effect).

Despite the many advantages of the use of alcohol as a cosurfactant, traces of it will be present on the final product and depending on the application; this presence may or may not be acceptable. According to the European laws (Directive 2009/32/CE, April 23, 2009), 1-butanol can be present in the final food product with a maximum quantity of $1 \mathrm{mg} / \mathrm{kg}$. On the contrary, ethanol is non-toxic and so can be used more safely in food [21] and pharmaceutical applications.

Effect of Brine. If an electrolyte, $\mathrm{NaCl}$, is added to the surfactant/water/organic solvent system, a system of four components is generated; however, it is possible to assume that the salt is confined to the aqueous domain [22], and consequently the quaternary map can be simplified to a pseudoternary one. Thus the substitution of water by $2 \%$ brine was investigated at different temperatures. The only difference observed was produced by the combination of the effect of the salt and temperature. At $40^{\circ} \mathrm{C}$, the emulsion area and gel-like region slightly increased with respect to the same system using water (results not shown).

This negative effect could be primarily attributed to two actions: a decrease in the superficial activity or a decrease of the CMC (critical micelle concentration), although both effects are usually negligible for non-ionic surfactants. Therefore, the action of the salt in the system should be explained by other reasons.

In the first place, the addition of an electrolyte $(\mathrm{NaCl})$ tends to decrease the hydrophilicity of the surfactant [23], so the system becomes more sensitive to the temperature, decreasing the cloud point (salting out) [24].

Secondly, the presence of ions disrupts the water structure, which affects the number of water molecules available for solvation [25].

Moreover, the presence of salt also modifies physical properties of the system such as the viscosity. This last effect is related to the growth of the micelles: electrolytes which cause the salting out tend to promote growth [26]. The larger the micelle size, the greater the viscosity of the mixture, promoting the growth of the emulsion area and the gel-like appearance. This effect was also observed by other authors who reported that the replacement of water by brine provoked the appearance of gel-like structures in the low emulsifier and higher oil proportion domain [27].

3.1.2. Effect of Temperature. In order to study the temperature effect of each system, a phase prism was built. Temperature effect depends on the type of surfactant, which is able to affect the action over the interface and/or the mutual solubility of the phases. Related to both actions, non-ionic surfactants, such as Tween 80, are known to show a temperaturedependent behaviour. With increasing temperature, dehydratation of the oxyethylene head groups of the surfactant molecule occurs and as a consequence the surfactant loses its hydrophilic character, becoming more lipophilic. The phase

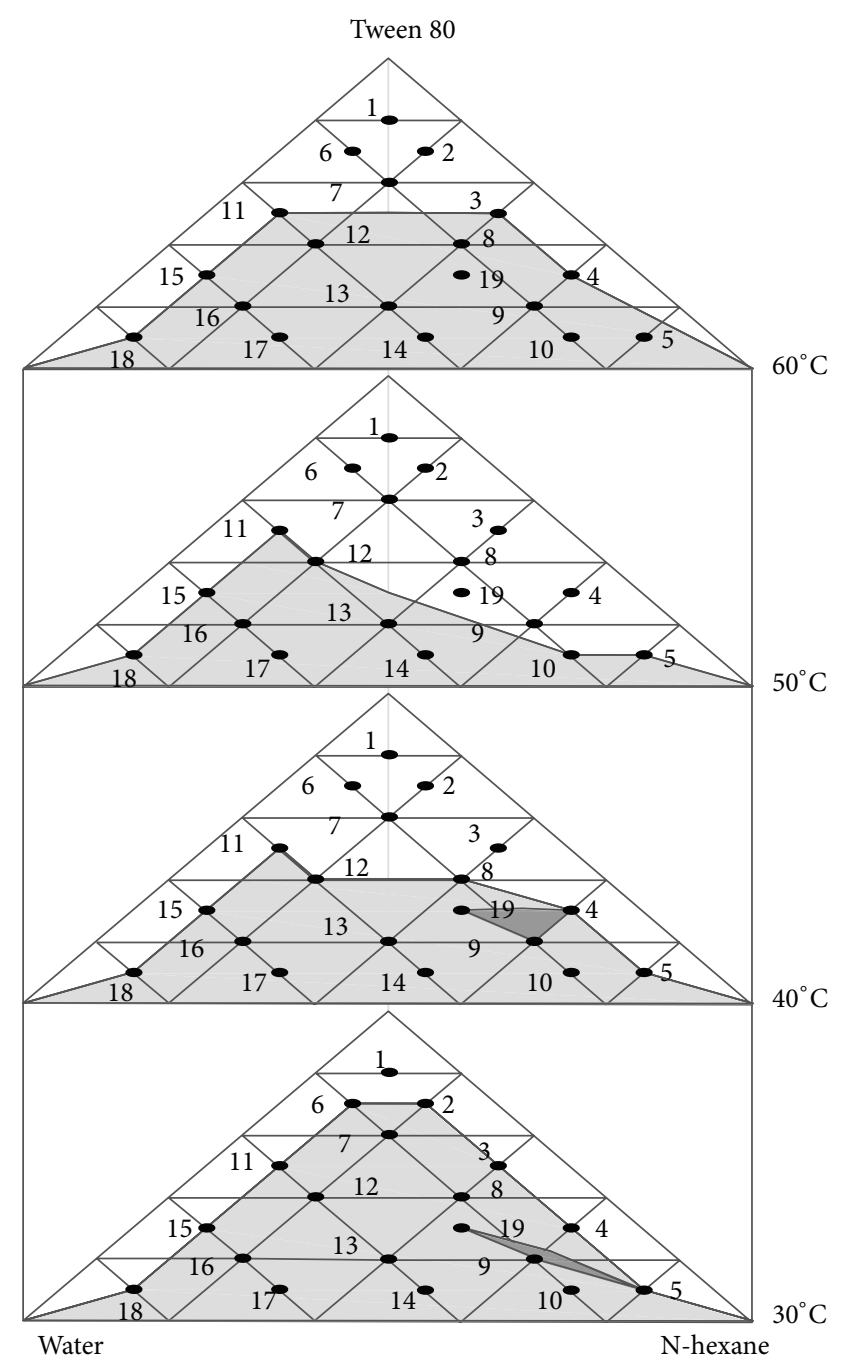

FIgURE 3: Phase prism corresponding with the Tween $80 /$ water/nhexane system.

prism for the Tween $80 /$ water/n-hexane system reflects this behaviour in Figure 3.

It was noted that when temperature was raised from $25^{\circ} \mathrm{C}$ to $30^{\circ} \mathrm{C}$, the gel-like region decreased as a result of a reduction in viscosity.

From $30^{\circ} \mathrm{C}$ to $40^{\circ} \mathrm{C}$, the microemulsion region increased as expected, due to the reduction of the hydrophilic character of the surfactant favouring the oil dissolution. However, at $40^{\circ} \mathrm{C}$ the gel-like region increased. The only explanation found for this unexpected result was that polyoxyethylene chains increased in length when the temperature rose above a point called the (phase inversion temperature) PIT [14], resulting in an increase of the micelle size and consequently in an increase of the viscosity.

From 40 to $50^{\circ} \mathrm{C}$, the gel-like region disappeared due to a viscosity reduction as an effect of the increase of temperature, and the emulsion region diminished. Moreover, the emulsion region shifted to the left as a consequence of the increase in the lipophilic character of the surfactant when high temperatures were reached. Therefore, more quantity 
of oil was dissolved, which favoured the formation of $\mathrm{W} / \mathrm{O}$ structures (see determination of the emulsions structure section) [18].

Finally, from 50 to $60^{\circ} \mathrm{C}$, the emulsion region increased as a result of reaching the cloud point (phase separation temperature) [6], as occurred in samples 3, 4, 9, and 19, which became turbid. This critical temperature is attained when the dehydratation of the oxyethylene head groups of the surfactant reaches a maximum, causing the micellar aqueous solution of the surfactant to demix into a surfactantrich phase and a water-rich phase. The cloud point depends on the molecular structure of the non-ionic surfactant, more specifically on the hydrophobic chain length and the number of oxyethylene units. However, this phenomenon was reversible: the solution became transparent when the temperature fell again to $50^{\circ} \mathrm{C}$.

When 1-butanol was added to the system (see Figure 4), it gained stability at room temperature as explained earlier; however, when temperature increased, this benefit was partially lost. For temperatures over $30^{\circ} \mathrm{C}$, turbidity increased as the temperature increased at the same time that the macroemulsion region shifted to the left. For example, at $40^{\circ} \mathrm{C}$ samples 11, 12, and 15 became turbid. This was an indication that in the presence of 1-butanol, the cloud point was reached at lower temperature than for the system without alcohol. This effect was also observed by other authors over a similar system [28]. On the other hand, sample 5 at $50^{\circ} \mathrm{C}$ became transparent as a result of an increase of the W/O structures, as explained earlier.

The behaviour of the Tween $80+$ ethanol/water/n-hexane system is shown in Figure 5. The phase behaviour kept the same tendencies outlined thus far. As temperature increased, emulsion region diminished. Similarly, at high temperatures the emulsion region shifted to the left; however, cloud point was not detected on the range of temperatures studied.

The difference between this system to the one with 1butanol was that the lowest temperature to obtain the ternary phase map was $30^{\circ} \mathrm{C}$; under this temperature phases were not miscible. It is explained in terms of the effect that temperature had on the surfactant action, as well as on the surfactant dissolution in phases [29]. As a result, a range of temperature is defined (lower critical temperature $\left(T_{\mathrm{lc}}\right)$ and upper critical temperature $\left(T_{\mathrm{uc}}\right)$ ), outside of which the three components of the system are not totally soluble. In this case, $T_{\mathrm{lc}}$ for the Tween 80 + ethanol/water/n-hexane system was $30^{\circ} \mathrm{C}$, below which it was impossible to achieve solvation between phases. It is worth noting that for the system without alcohol and the system with 1-butanol this temperature was under $25^{\circ} \mathrm{C}$. The reason why this temperature for the system with ethanol was lower than that for the system without alcohol is that the amount of surfactant was lower and the ethanol was unable to stabilise the system at this temperature by itself.

3.1.3. Selection of Conditions for Further Applications. A comparison of the results produced by each parameter was made with the objective of carrying out an easier selection of the operational conditions, in a pharmaceutical potential application of this type of systems. Figure 6 shows a summary

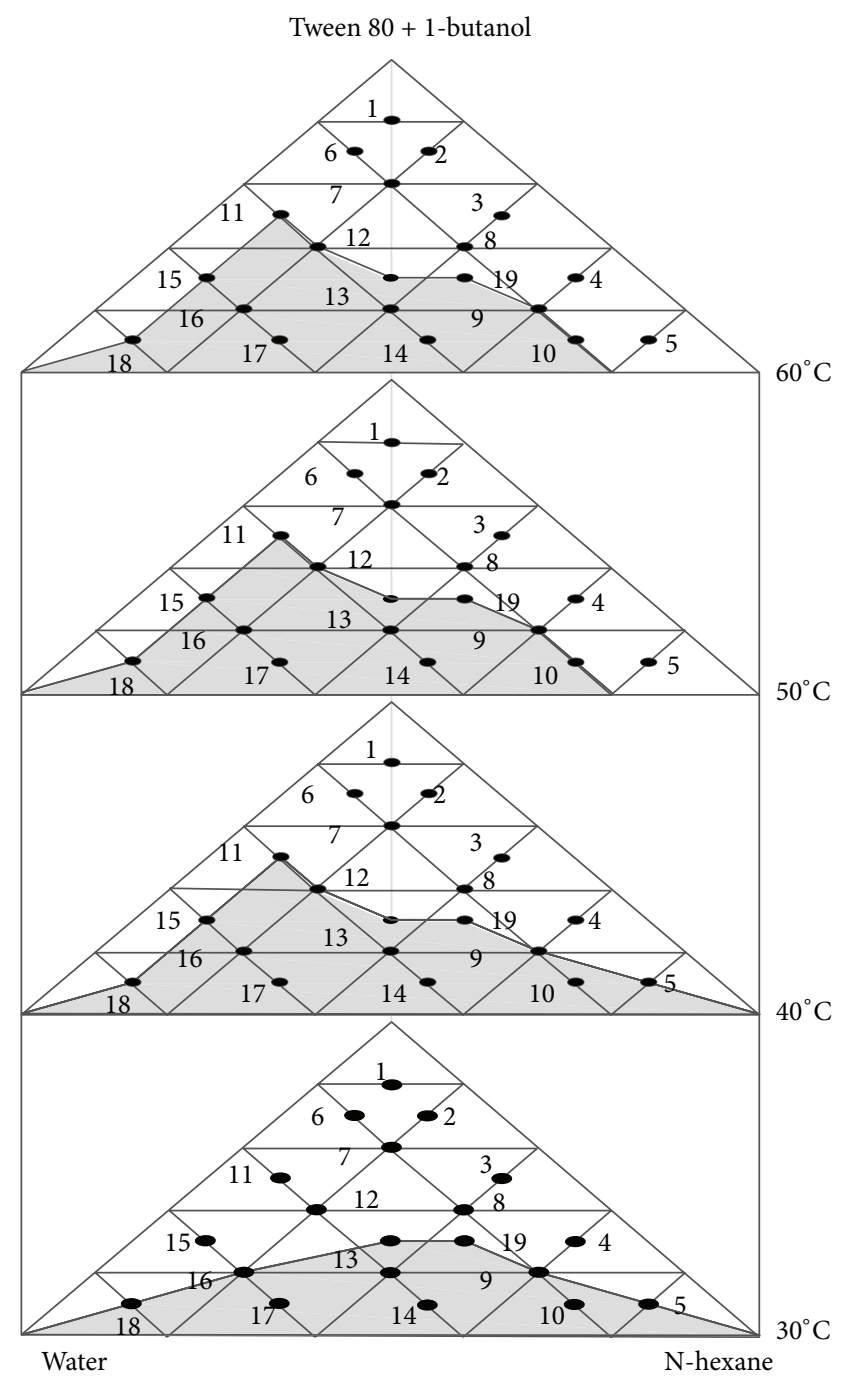

FIgUre 4: Phase prism corresponding with the Tween $80+1$ butanol/water/n-hexane system.

of the foregoing purposes, detailing the extension of each region and the minimum amount of surfactant needed to get microemulsions. The gel-like region was not considered.

The basic case of reference is the system without additives at room temperature $\left(25^{\circ} \mathrm{C}\right)$. This system showed a lack of stability, which is reflected by the high extension of macroemulsion region, around $65 \%$. Just one sample of microemulsion was obtained, for which it was necessary to add $80 \%$ of surfactant.

The effect of temperature is represented by the second and third columns. The second one shows the effect of the temperature under the cloud point $\left(60^{\circ} \mathrm{C}\right)$. The microemulsion area increased to about $60 \%$, needing only $40 \%$ of surfactant. When temperature exceeded the cloud point (third column), turbidity increased to almost $60 \%$.

The fourth column demonstrates the benefits achieved by adding an alcohol as cosurfactant, in this case 1-butanol, which can be summarised in an increase of the microemulsion area (67\%), a decrease in the macroemulsion area, and 


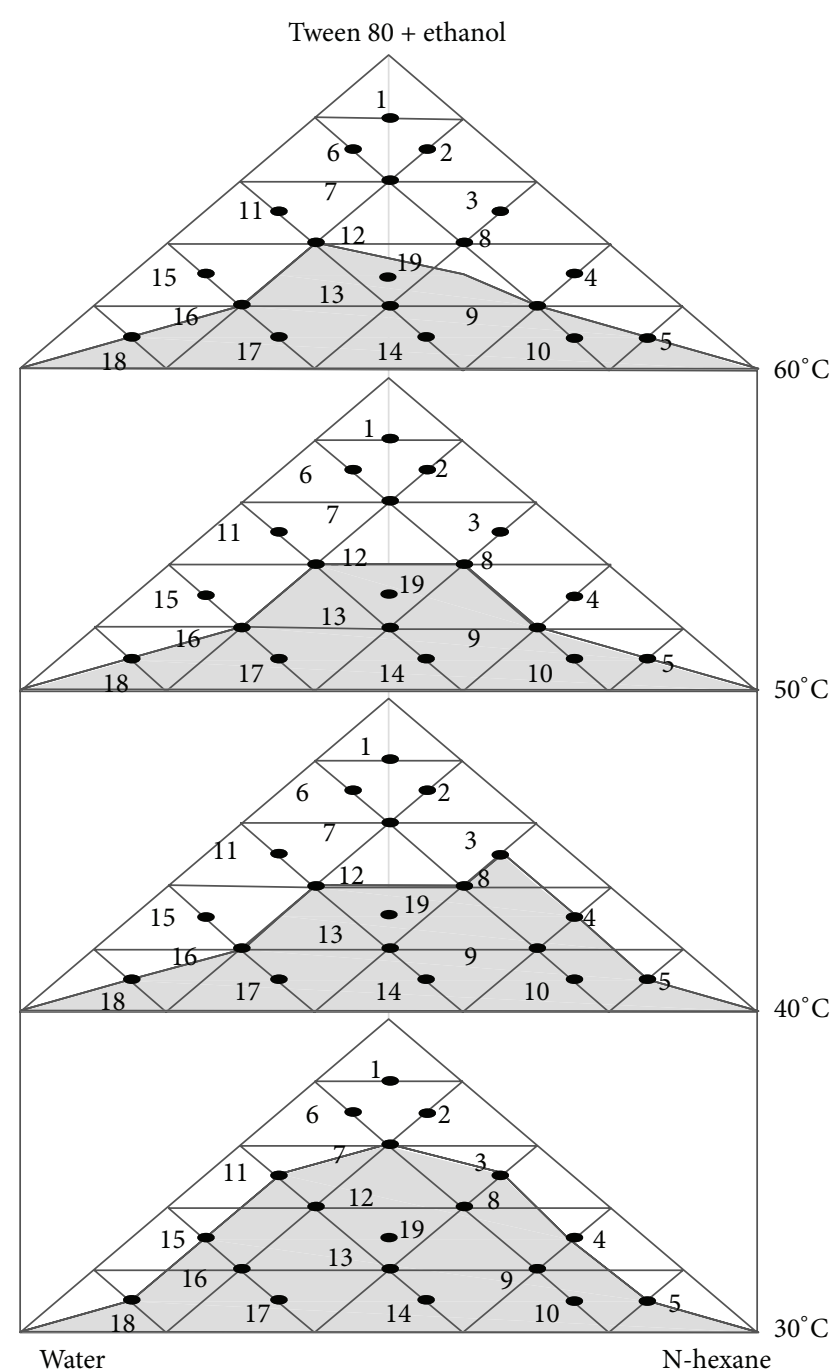

FIGURE 5: Phase prism for the Tween 80 + ethanol/water/n-hexane system.

disappearance of the gel-like region. All of it achieved with only $30 \%$ of surfactant. The reasons could be attributed to an improvement of the solubility of the surfactant in the oil phase and to several physical effects that ended up enhancing the superficial activity of the surfactant at the interface.

However, these benefits are only possible in a narrow interval of temperatures since the cloud point of the surfactant was diminished to $40^{\circ} \mathrm{C}$, as shown in the fifth column. Thus, turbidity increased again as well as the amount of surfactant needed to get transparent microemulsions. It is worth noting that when ethanol was used, the cloud point was not detected under $60^{\circ} \mathrm{C}$, showing larger areas of microemulsion at high temperatures (around 63\%) with only $30 \%$ of surfactant. Therefore, depending on the working temperature, a different alcohol could be required to stabilise the system.

Thus, according to the final application, all these variables have to be counterbalanced to obtain the specific characteristic of the required type of emulsion.

Frequently, it is preferable to work with macroemulsions since they are several times cheaper than microemulsions,

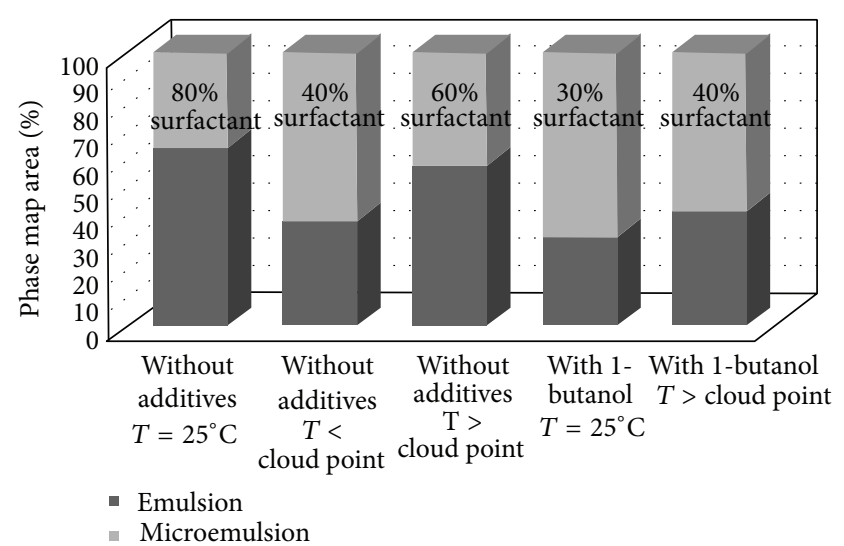

Figure 6: Comparison between the effects on the extension of emulsion and microemulsion region and the minimum amount of surfactant needed for each case.

and they have a wide range of operational conditions for obtainment processes. However, microemulsions provide the product with high stability, and also, for example, in pharmaceutics, better drug delivery $[30,31]$ and in cosmetics, better skin penetration [32, 33]. For the studied system, the best combination for obtaining microemulsions depends on the temperatures allowed for process and product: at room temperature the most advisable would be to include 1butanol; between 40 to $60^{\circ} \mathrm{C}$, it might be advisable not to use cosurfactant and to just play with the temperature. If high temperatures (around $60^{\circ} \mathrm{C}$ ) are required, then the choice should be to add ethanol. On the other hand, if surfactant concentration is kept low (less than 1\%) macroemulsions would be favoured.

3.2. Determination of the Emulsions Structure. Emulsion formation and stability depend on many factors, among which the structure is of great importance. This term refers to the type of phase: $\mathrm{W} / \mathrm{O}$, bicontinuous, or $\mathrm{O} / \mathrm{W}$; they are very important, because the structure together with micelle size affects hydrodynamics and interfacial science and even determines the applications. Definition of the structure of an emulsion is sometimes difficult to predict from solvent ratio, especially at close solvent proportions. Thus, other techniques such as conductimetry have to be used.

The type of emulsion can be deducted from the conductivity value. Since neither the organic phase nor the non-ionic surfactant is conductive, an electrolyte had to be added to the aqueous solution to provide electrical charge to the mixture. Thus, water was replaced in conductivity measurements by $2 \%$ brine $(\mathrm{NaCl})$. As shown earlier, the areas of the microdomains remained the same when this replacement was done.

The resulting structures at $25^{\circ} \mathrm{C}$ for the systems Tween 80 + 1-butanol/brine/n-hexane and Tween 80 + ethanol/brine/nhexane are shown in Figures 7 and 8.

In both systems, there is a predominance of $\mathrm{O} / \mathrm{W}$ over bicontinuous and W/O structures. According to Bancroft's rule, $\mathrm{O} / \mathrm{W}$ emulsions are produced by emulsifying agents that are more soluble in the "water" than in the "oil" phase, 


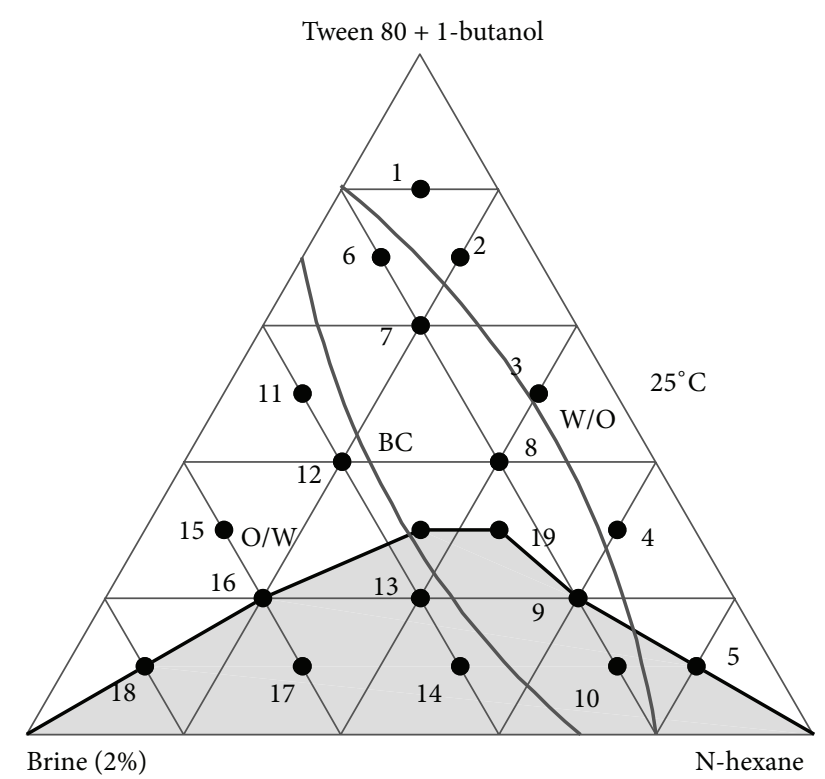

FIgURE 7: Structural classification for the system: Tween $80+1-$ butanol/brine/n-hexane.

whereas $\mathrm{W} / \mathrm{O}$ emulsions are produced by emulsifier agents that are more soluble in "oil" than in "water." Therefore, as the Tween 80 is a water-soluble compound, it tends to form $\mathrm{O} / \mathrm{W}$ emulsion. This conclusion could also be obtained by using the HLB concept. According to this parameter, HLB values between 3.5 and 6 promote the formation of $\mathrm{W} / \mathrm{O}$ emulsions and values between 8 and 18, O/W [34]. Since Tween 80 has an HLB of 15, O/W emulsions predominated in both systems.

The same tendency was observed by other authors using Tween $80+1$-butanol in a ratio of $2: 1$, where $\mathrm{O} / \mathrm{W}$ structures predominated and the bicontinuous region on average started at around $12 \%$ of water [35].

As stated before, an increase in temperature should provoke an increase in the W/O region, but with our equipment it was impossible to corroborate this.

The structural classification for systems using 1-butanol and ethanol was very similar and the main differences were found on the extension of the bicontinuous region. This could be caused by the difference in chain length. In this sense, the fact that ethanol has a shorter chain provides a lower capacity than 1-butanol to improve the solubility of Tween 80 in the oil phase according to Traube's rule. Consequently, the bicontinuous region, for being an unstable transition structure, became smaller.

\section{Conclusion}

The water/n-hexane system with the non-toxic, biodegradable, and non-ionic surfactant, Tween 80 , was studied according to phase behaviour and structure, broadening previous researches made in a similar system, which were concentrated in temperature effect and molecular structure, respectively $[27,35]$. In our study concretely, the effect of additives such as alcohols (1-butanol and ethanol) and brine was considered

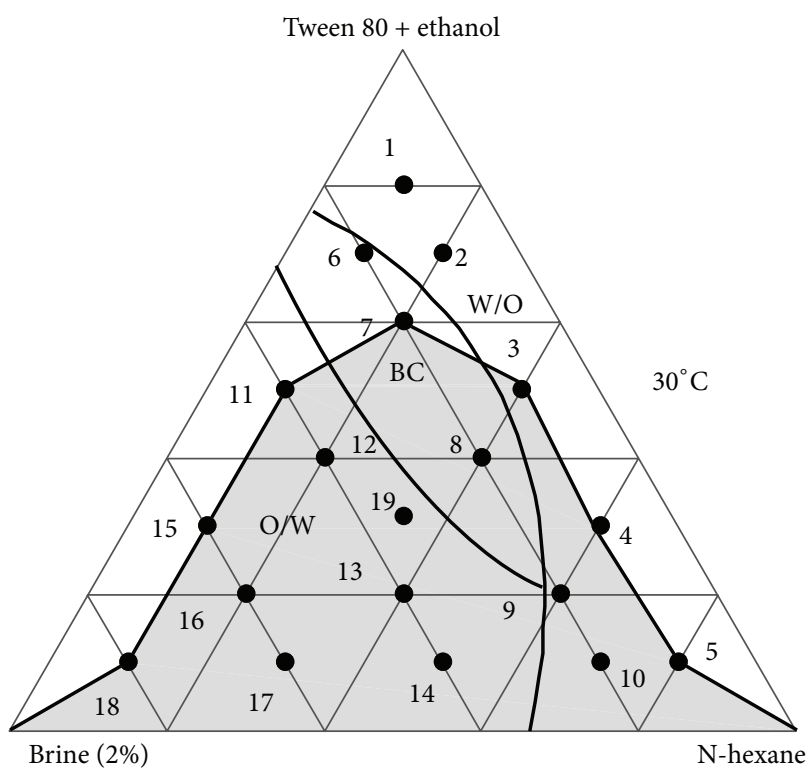

FIGURE 8: Structural classification for the Tween 80 + ethanol/brine/ n-hexane system.

as well as their combined influence with temperature. In addition, emulsions structure was analyzed.

The aim of the variations over the original system was always the same: to increase the stability. In the first attempt, alcohols enhanced the solubility of the surfactant in the oil phase and decreased the mixture viscosity. As a result and in accordance with the basic principles of fluid dynamics and interfacial science, the superficial activity of the surfactant increased. However, the cosurfactant action of the alcohols depended on their carbon chain length according to Traube's rule [18]; thus, 1-butanol was more effective at room temperature.

On the other hand, taking into account the influence of thermodynamics over our colloidal system [16], the solubility of the surfactant in the oil phase could be increased by an augment of temperature favouring the expansion of the microemulsion area. Nevertheless, this effect was lost when the cloud point was reached at $60^{\circ} \mathrm{C}$, because the surfactant solubility in the aqueous phase decreased, destabilizing the system and thus increasing the turbidity. It is important to note that the presence of 1-butanol decreased this temperature to $40^{\circ} \mathrm{C}$ but for ethanol the cloud point was not detected up to $60^{\circ} \mathrm{C}$.

The structure was directly dependent on the surfactant solubility in both phases according to Bancroft's rule [34]. Due to the greater solubility of the Tween 80 in the water phase the predominant structure at room temperature was $\mathrm{O} / \mathrm{W}$, although W/O microemulsions could be obtained by increasing the temperature as a consequence of the enhanced surfactant solubility in the oil phase.

This comprehensive analysis of the system allows the establishment of the best formulation and operational conditions at the lowest possible surfactant concentration (to reduce costs) for potential pharmaceutical applications. In this system, microemulsions could be favoured at relatively 
low surfactant concentration (around 30\%) by addition of an alcohol or by increasing temperature. Evidently, this selection must be done according to the final application which will provide some restrictions to the system. In this sense, when microemulsions are used as colloidal nanocarriers, the drug to be delivered may condition the system composition, the temperature or even limit the use of the alcohol. Similar argumentations are valid if the microemulsions are to be used for enzymatic reactions or excipient processing.

\section{References}

[1] M. Lancaster, "Principles of sustainable and green chemistry," in Handbook of Green Chemistry and Technology, J. Clark and D. Macquarrie, Eds., pp. 10-27, Blackwell Science, Oxford, UK, 2002.

[2] D. J. C. Constable, P. J. Dunn, J. D. Hayler et al., "Key green chemistry research areas-a perspective from pharmaceutical manufacturers," Green Chemistry, vol. 9, no. 5, pp. 411-420, 2007.

[3] G. Barnes and I. Gentle, Interfacial Science: An Introduction, Oxford University Press, 2005.

[4] K. Shinoda and B. Lindman, "Organized surfactant systems: microemulsions," Langmuir, vol. 3, no. 2, pp. 135-149, 1987.

[5] Y.-Y. Luk and N. L. Abbott, "Applications of functional surfactants," Current Opinion in Colloid and Interface Science, vol. 7, no. 5-6, pp. 267-275, 2002.

[6] B. A. Kerwin, "Polysorbates 20 and 80 used in the formulation of protein biotherapeutics: structure and degradation pathways," Journal of Pharmaceutical Sciences, vol. 97, no. 8, pp. 2924-2935, 2008.

[7] B. K. Paul and S. P. Moulik, "Microemulsioins: an overview," Journal of Dispersion Science and Technology, vol. 18, no. 4, pp. 301-367, 1997.

[8] S. P. Moulik and B. K. Paul, "Structure, dynamics and transport properties of micro emulsions," Advances in Colloid and Interface Science, vol. 78, no. 2, pp. 99-195, 1998.

[9] S. P. Moulik and A. K. Rakshit, "Physicochemisty and applications of microemulsions," Journal of Surface Science and Technology, vol. 22, no. 3-4, pp. 159-186, 2006.

[10] C. T. Lee Jr., W. Ryoo, P. G. Smith Jr. et al., "Carbon dioxidein-water microemulsions," Journal of the American Chemical Society, vol. 125, no. 10, pp. 3181-3189, 2003.

[11] M. Haruki, K. Matsuura, Y. Kaida, S.-I. Kihara, and S. Takishima, "Microscopic phase behavior of supercritical carbon dioxide + non-ionic surfactant + water systems at elevated pressures," Fluid Phase Equilibria, vol. 289, no. 1, pp. 1-5, 2010.

[12] W. Peter Wuelfing, K. Kosuda, A. C. Templeton, A. Harman, M. D. Mowery, and R. A. Reed, "Polysorbate $80 \mathrm{UV} /$ vis spectral and chromatographic characteristics-defining boundary conditions for use of the surfactant in dissolution analysis," Journal of Pharmaceutical and Biomedical Analysis, vol. 41, no. 3, pp. 774-782, 2006.

[13] H. Kahl, K. Quitzsch, and E. H. Stenby, "Phase equilibria of microemulsion forming system $\mathrm{n}$-decyl- $\beta$-D-glucopyranoside/ water/n-octane/1-butanol," Fluid Phase Equilibria, vol. 139, no. 1-2, pp. 295-309, 1997.

[14] J. L. Salager, L. Márquez, I. Mira, A. Peña, E. Tyrode, and N. B. Zambrano, "Principles of emulsion formulation engineering," in Adsorption and Aggregation of Surfactants in Solution, K. L. Mittal and D. O. Shah, Eds., vol. 109 of Surfactant Science Series, pp. 501-524, Marcel Dekker, New York, NY, USA, 2002.
[15] D. G. Peck and K. P. Johnston, "Theory of the pressure effect on the curvature and phase behavior of AOT/propane/brine waterin-oil microemulsions," Journal of Physical Chemistry, vol. 95, no. 23, pp. 9549-9556, 1991.

[16] M. Kahlweit, R. Strey, and G. Busse, "Microemulsions: a qualitative thermodynamic approach," Journal of Physical Chemistry, vol. 94, no. 10, pp. 3881-3894, 1990.

[17] M. Porras, C. Solans, C. González, A. Martínez, A. Guinart, and J. M. Gutiérrez, "Studies of formation of W/O nano-emulsions," Colloids and Surfaces A, vol. 249, pp. 115-118, 2004.

[18] D. Attwood and A. T. Florence, Surfactant Systems. Their Chemistry, Pharmacy and Biology, Chapman and Hall, New York, NY, USA, 1983.

[19] S. Reekmans, H. Luo, M. Van Der Auweraer, and F. C. De Schryver, "Influence of alcohols and alkanes on the aggregation behavior of ionic surfactants in water," Langmuir, vol. 6, no. 3, pp. 628-637, 1990.

[20] Y. Bayrak and M. Iscan, "Studies on the phase behavior of the system non-ionic surfactant/alcohol/ alkane/ $\mathrm{H}_{2} \mathrm{O}$," Colloids and Surfaces A, vol. 268, no. 1-3, pp. 99-103, 2005.

[21] A. Yaghmur, A. Aserin, and N. Garti, "Phase behavior of microemulsions based on food-grade nonionic surfactants: effect of polyols and short-chain alcohols," Colloids and Surfaces A, vol. 209, no. 1, pp. 71-81, 2002.

[22] J. Sjöblom, R. Lindberg, and S. E. Friberg, "Microemulsionsphase equilibria characterization, structures, applications and chemical reactions," Advances in Colloid and Interface Science, vol. 65, pp. 125-287, 1996.

[23] W. Warisnoicharoen, A. B. Lansley, and M. J. Lawrence, "Nonionic oil-in-water microemulsions: the effect of oil type on phase behaviour," International Journal of Pharmaceutics, vol. 198, no. 1, pp. 7-27, 2000.

[24] S. Ajith and A. K. Rakshit, "Effect of $\mathrm{NaCl}$ on a nonionic surfactant microemulsion system," Langmuir, vol. 11, no. 4, pp. 1122-1126, 1995.

[25] H. Coulombeau, F. Testard, T. Zemb, and C. Larpent, "Effect of recognized and unrecognized salt on the self-assembly of new thermosensitive metal-chelating surfactants," Langmuir, vol. 20, no. 12, pp. 4840-4850, 2004.

[26] H. Schott, "Salting in of nonionic surfactants by complexation with inorganic salts," Journal of Colloid And Interface Science, vol. 43, no. 1, pp. 150-155, 1973.

[27] P. Mukherjee, S. K. Padhan, S. Dash, S. Patel, P. K. Mohapatra, and B. K. Mishra, "Effect of temperature on pseudoternary system Tween-80-butanol-hexane-water," Journal of Colloid and Interface Science, vol. 355, no. 1, pp. 157-163, 2011.

[28] S. Y. Shiao, V. Chhabra, A. Patist et al., "Chain length compatibility effects in mixed surfactant systems for technological applications," Advances in Colloid and Interface Science, vol. 74, no. 1-3, pp. 1-29, 1998.

[29] J. L. Salager, "Phase transformation and emulsion inversion on the basis of catastrophe theory," in Encyclopedia of Emulsion Technology, P. Becker, Ed., vol. 3 of Basic Theory Measurement Applications, pp. 79-134, Marcel Dekker, New York, NY, USA, 1988.

[30] F. Podlogar, M. Gašperlin, M. Tomšič, A. Jamnik, and M. B. Rogač, "Structural characterisation of water-Tween 40/Imwitor 308-isopropyl myristate microemulsions using different experimental methods," International Journal of Pharmaceutics, vol. 276, no. 1-2, pp. 115-128, 2004. 
[31] P.-C. Wu, Y.-H. Lin, J.-S. Chang, Y.-B. Huang, and Y.-H. Tsai, "The effect of component of microemulsion for transdermal delivery of nicardipine hydrochloride," Drug Development and Industrial Pharmacy, vol. 36, no. 12, pp. 1398-1403, 2010.

[32] S. Hoeller, A. Sperger, and C. Valenta, "Lecithin based nanoemulsions: a comparative study of the influence of non-ionic surfactants and the cationic phytosphingosine on physicochemical behaviour and skin permeation," International Journal of Pharmaceutics, vol. 370, no. 1-2, pp. 181-186, 2009.

[33] A. Azeem, Z. I. Khan, M. Aqil, F. J. Ahmad, R. K. Khar, and S. Talegaonkar, "Microemulsions as a surrogate carrier for dermal drug delivery," Drug Development and Industrial Pharmacy, vol. 35, no. 5, pp. 525-547, 2009.

[34] K. Holmberg, B. Jönsson, B. Kronberg, and B. Lindman, Surfactants and Polymers in Aqueous Solution, John Wiley \& Sons, 2002.

[35] H. P. Mishra, N. Jyotish, S. Panigrahi, and P. K. Misra, “Organization of amphiphiles, part IX: effect of molecular structure of cosurfactants and oils on the phase behavior of tween-80: alkanol-oil-water systems," Journal of Dispersion Science and Technology, vol. 30, no. 4, pp. 564-574, 2009. 

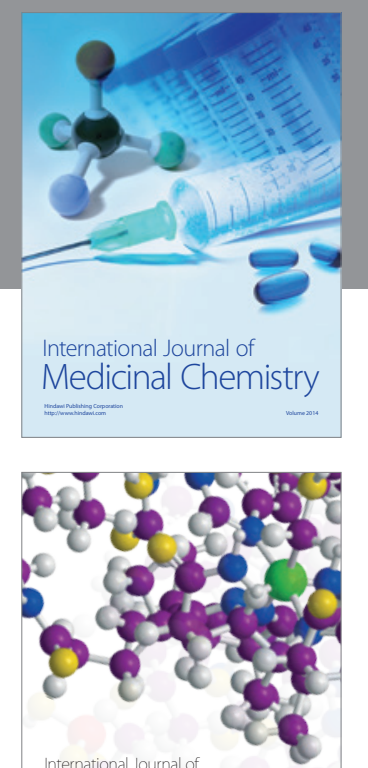

\section{Carbohydrate} Chemistry

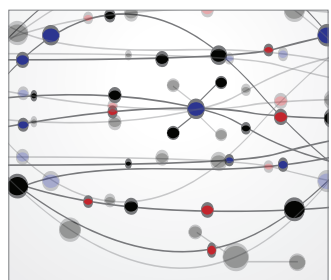

The Scientific World Journal
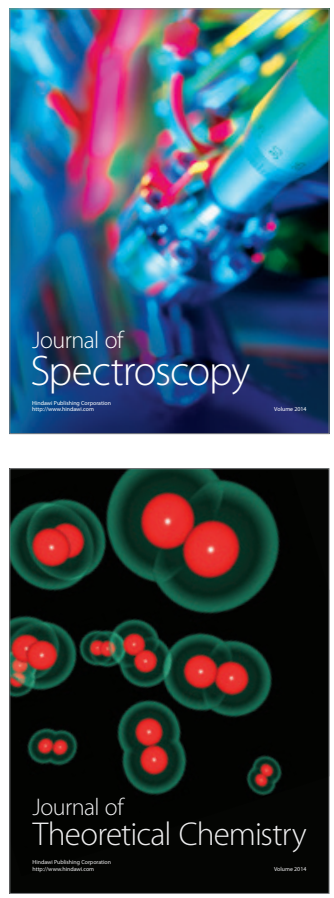
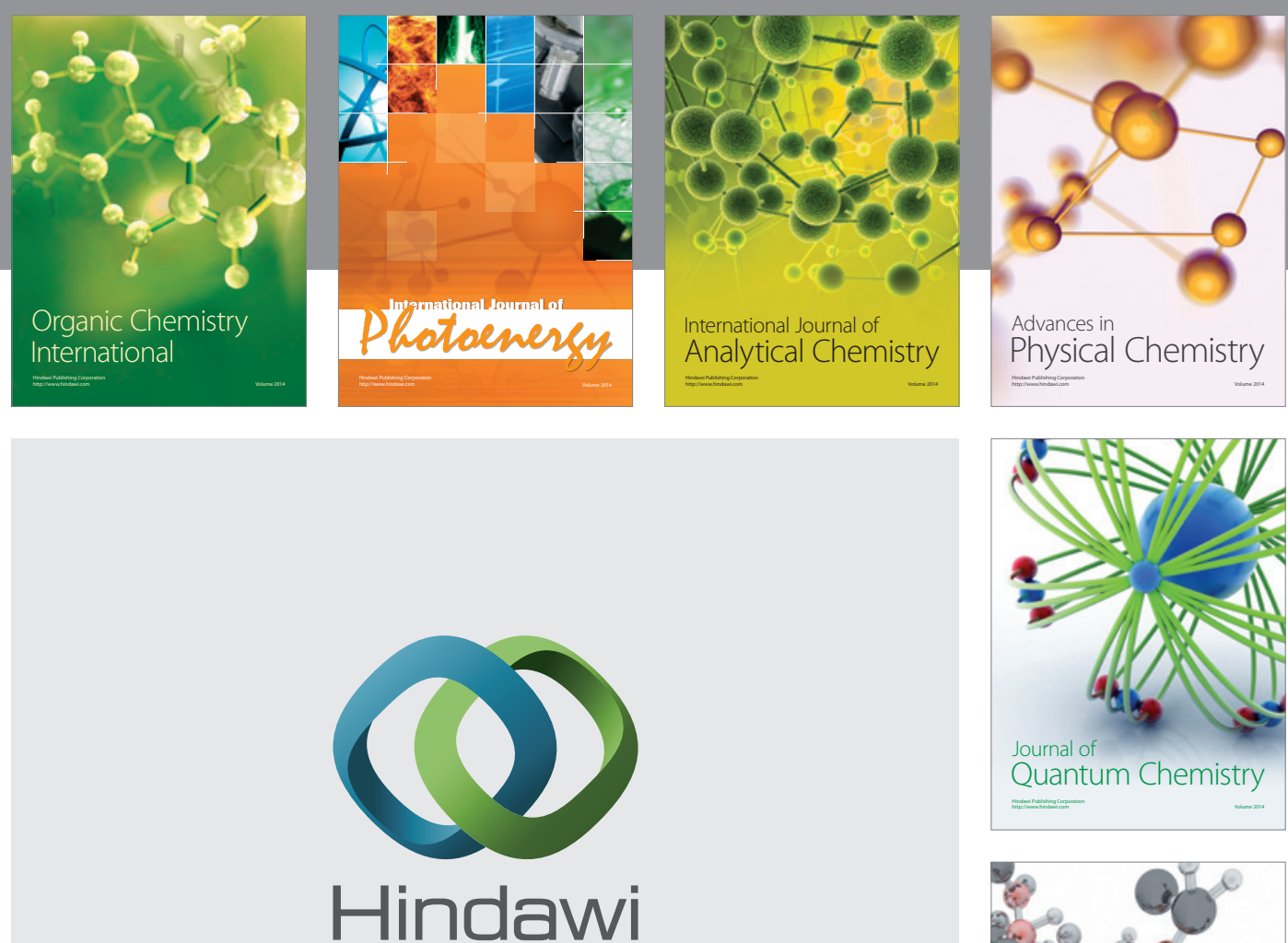

Submit your manuscripts at

http://www.hindawi.com

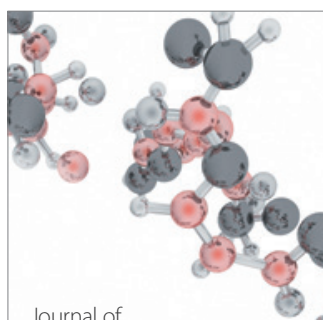

Analytical Methods

in Chemistry

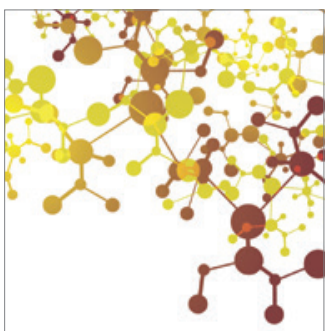

Journal of

Applied Chemistry

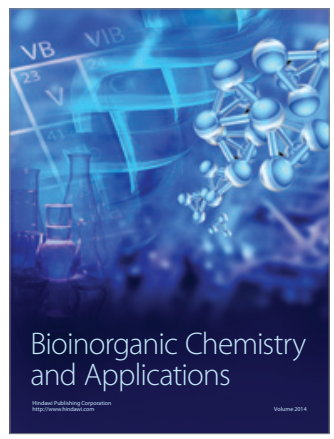

Inorganic Chemistry
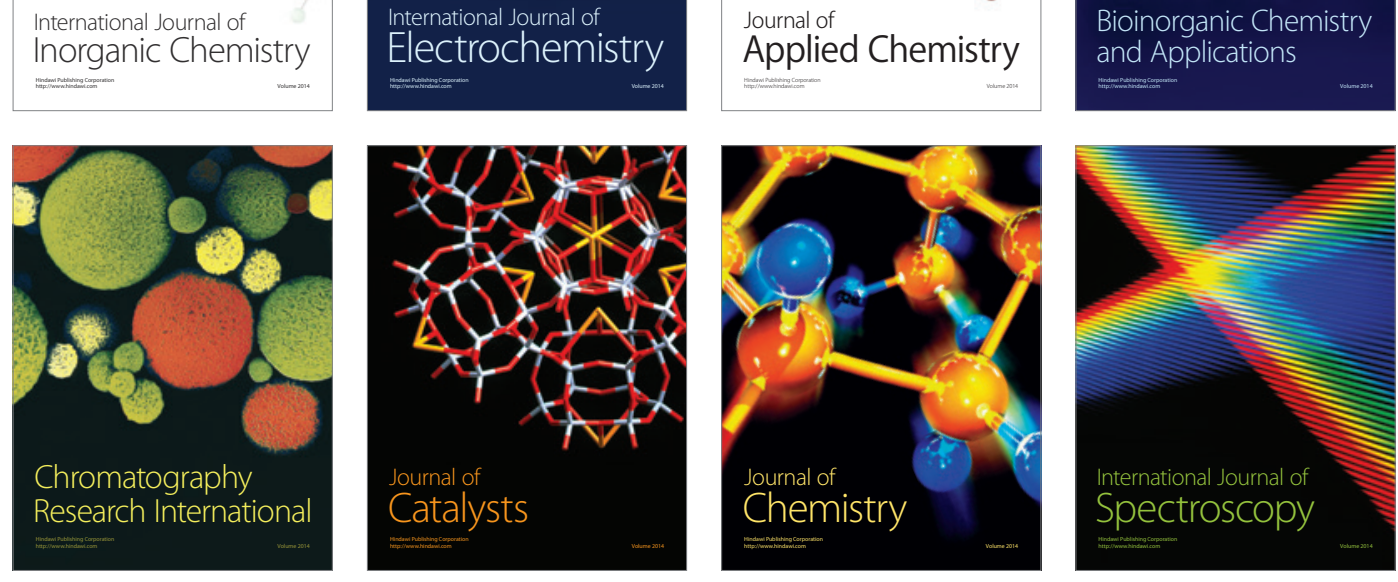